\title{
Introducing Short Stories in EFL Classroom to Explore Culturally Diverse Issues
}

\author{
Amina Berrarbi \\ Department of English, Faculty of Letters and languages \\ University of Abdelhamid Ibn Badis, Mostaganem, Algeria \\ Abbes Bahous \\ Department of English, Faculty of Letters and languages \\ University of Abdelhamid Ibn Badis, Mostaganem, Algeria
}

\begin{abstract}
The present paper attempts to highlight the use of short stories as an initial motivational literary genre in English as a Foreign Language (EFL) context. It also aims at providing some practical ideas and methods regarding the use of short stories by inquiring about the following questions: What significance can be accorded to the use of short stories in EFL classroom and how can short stories serve as a mediator between the learner's own culture and other cultures? To address these questions, a questionnaire was collected from 95 third year undergraduate students at Mostaganem University, 24 of the students were selected randomly for an intervention that lasted about 8 weeks. Findings from the questionnaire and experimental study indicate that the study population does not only show positive attitudes towards short stories reading but also manifests a number of signs that reflect their acquisition of cultural issues, they also support the usefulness of examining learners' cultural knowledge, feelings and experiences before, while and after bringing short stories into the literature class. Therefore, it is recommended to use short stories as a primary motivational reading material to stimulate students' cultural awareness and their reading envy. Key words: culture, cultural diversity, identity, motivation, short stories
\end{abstract}

Cite as: Berrarbi, A., \& Bahous, A. (2018). Introducing Short Stories in EFL Classroom to Explore Culturally Diverse Issues. Arab World English Journal for Translation \& Literary Studies, 2 (1). DOI: http://dx.doi.org/10.24093/awejtls/vol2no2.7 